1 Maestría en Radiología Bucal y Maxilofacial, Escuela de Odontología,Universidad Científica del Sur - UCSUR, Lima, Perú, Cirujano Dentista de la Universidad Juárez del Estado de Durango, México.

2 Profesor Asociado de la Maestría en Radiología Bucal y MaxiloFacial de la Escuela de Odontología, Universidad Científica del Sur - UCSUR, Lima, Perú.

3 Profesor Asociado de la Maestría en Radiología Bucal y MaxiloFacial de la Escuela de Odontología, Universidad Científica del Sur - UCSUR, Lima, Perú y Universidad del Bosque, Bogotá, Colombia.

\title{
LINFOMA DIFUSO DE CÉLULAS GRANDES INMUNOFENOTIPO "B" EN REGIÓN GENIANA: REPORTE DE UN CASO
}

\begin{abstract}
RESUMEN
El linfoma difuso de células grandes B (LDCGB) constituye 30 a 40\% de los linfomas no Hodgkin (LNH) del adulto, se caracterizan por un patrón de crecimiento difuso remplazando el tejido linfoide normal y el tamaño de las células es catalogado por el tamaño nuclear, según la actual clasificación de neoplasias hematolinfoides de la OMS. El siguente reporte presenta un caso de un linfoma difuso de células grandes inmunofenotipo B en región geniana el cual no es frecuente en dicha region, teniendo como objetivo dar a conocer una variante mas de su localizacion, manteniendo informado al lector sobre la aparicion no frecuente de esta lesion neoplásica
\end{abstract}

PALABRAS CLAVE: Linfoma Difuso de Células Grandes Inmunofenotipo B Linfoma No Hodgkin, Linfona Hodgkin, Virus de Epstein-Bar.

\section{DIFFUSE OF BIG CELLS INMUNOFENOTYPE B IN GENIAN REGION: REPORT OF A CASE}

\section{ABSTRACT}

Diffuse large B-cell lymphoma (LDCGB) it constitutes 30 to $40 \%$ of non-Hodgkin lymphoma (NHL) in adult, are characterized by diffuse growth pattern replacing the normal lymphoid tissue and cell size is listed by the nuclear size, according to the current classification of neoplasms hematolymphoid WHO. The below report a case of a diffuse large cell lymphoma immunophenotype $b$ in geniana region which is rare in this region and provide a variant of its location is presented, kee ping informed the reader about the rare occurrence of this neoplastic lesion.

KEY WORDS: Diffuse Large Cell Type B, Lymphoma No Hodgkin, Linfona Hodgkin, Epstein-Bar Virus. 


\section{INTRODUCCIÓN}

El linfoma B difuso de células grandes (LDCGB) constituye 30 a $40 \%$ de los linfomas no Hodgkin (LNH) del adulto en países occidentales, siendo una neoplasia del sistema inmunitario de origen extranodal, derivado de células B $(65 \%)$ y de pronóstico favorable en la mayoría de casos. ${ }^{1-3}$ La edad promedio en la que se presenta es de 70 años; es muy agresivo y común en países en vías de desarrollo, particularmente en pacientes con inmunodeficiencia, el $40 \%$ son extra ganglionares, pero en pacientes con SIDA o algún otro tipo de inmunosupresión, pueden originarse en órganos internos en el $60 \%$ de los casos. ${ }^{4}$ Usualmente se originan de novo (primarios), otras veces representan progresión o transformación de otro linfoma menos agresivo (leucemia linfocítica crónica, linfoma de linfocitos pequeños, linfoma folicular) y se denomina LBDCG secundario. ${ }^{5} \mathrm{El}$ virus de Epstein-Barr es de los más importantes, puede dar origen a procesos linfo-proliferativos en pacientes con LDCGB e inmunodeficiencias congénitas o inmunodepresión prolongada post-trasplante, que hayan recibido quimioterapia de mantenimiento. ${ }^{6}$

Se caracterizan por tener un patrón de crecimiento difuso remplazando el tejido linfoide normal y el tamaño de las células es catalogado por el tamaño nuclear, según la actual clasificación de neoplasias hematolinfoides de la Organización Mundial de la Salud (OMS). ${ }^{5}$ Los cambios citológicos difieren según las variantes morfológicas como son: Centroblástico, inmunoblástico, plasmablástico, rico en histiocitos y células $\mathrm{T}$, la variante anaplásica y con expresión a ALK (cinasa de linfoma anaplásico). Los subtipos clínicos corresponden a las siguientes entidades: linfoma de células $\mathrm{B}$ primario del mediastino, linfoma intravascular, linfoma de cavidades serosas y granulomatosis linfomatoide. ${ }^{7}$ La mayor parte de LDCGB son positivos para diferentes marcadores pan $\mathrm{B}$, como CD20, CD19, CD79 a, también presentan expresión variable para CD45, CD30, CD5 y ALK. ${ }^{5}$ La sintomatología es muy variada y depende del subtipo histológico, la rapidez de crecimiento, la localización inicial, la edad y circunstancias particulares. El $40 \%$ de los casos los pacientes con LNH presentan síntomas generales como fiebre, pérdida de peso o sudoración profusa que no son explicables por otras causas. Otro tipo de síntomas locales, como cefalea, tos, dificultad para respirar, dolor óseo o abdominal pueden indicar afectación a esos niveles de la enfermedad. ${ }^{8}$ Alrededor del $80 \%$ de los LNH con compromiso óseo presentan cambios osteolíticos erosivos en las radiografías, otros tienen una apariencia radiográfica esclerótica o mixta. Algunas veces se pueden observar grandes masas de tejidos blandos extraóseos con destrucción cortical mínima en las radiografías simples, en cambio las imágenes por tomografía computarizada (TC) y resonancia magnética nuclear ayudan a visualizar con claridad estos cambios, así como el patrón de destrucción ósea trabecular y el reemplazo de la médula ósea, que generalmente son característicos de los tumores agresivos. ${ }^{9}$

La clasificación de la Revised European-American Lymphoma (REAL) se basa histopatológicamente en métodos morfológicos, de inmunofenotipos y moleculares para el diagnóstico de diferentes tipos de linfoma..$^{10} \mathrm{El}$ diagnóstico de linfomas requiere de material suficiente por el especimen quirúrgico, biopsia excisional de ganglio linfatico o biopsia de tejido extranodal. Algunas lesiones pueden abordarse por biopsia percutanea con aguja de corte bajo, guia ecografica o tomografía computarizada. El diagnóstico patológico debe realizarse de acuerdo con la clasificación de la OMS debido a que el subtipo histológico tendra una gran relevancia para el tratamiento..$^{11-13}$ Esta clasificación es parte esencial de la segunda clasificación de la OMS para tumores de tejido linfoide y hematopoyetico. Tablas 1 y $2{ }^{14}$ En este reporte se presenta un caso de un linfoma difuso de células grandes inmunofenotipo "B" en región geniana el cual no es frecuente en dicha region teniendo como objetivo conocer una variante mas de su localizacion, asi como mantener informado al lector hasta donde puede llegar la aparición de una lesión neoplásica. 
Tabla 1. DESCRIPCIÓN DE LINFOMAS

\begin{tabular}{l} 
LH \\
\hline \multicolumn{1}{|c|}{ Incidencia en países industrializados en 4} \\
por 100,000 . \\
Mortalidad en EUA 20071,070 de 8,190 ca- \\
sos registrados.
\end{tabular}

Pico máximo bimodal de incidencia;

1 pico; grupo de edad entre 20 y 30 años.

2 pico; grupo por arriba de los 50 años.

Se presenta con más frecuencia en raza blanca.

Se presenta como esclerosis nodular en el $70 \%$ de los casos, seguida de la variedad de celularidad mixta en $25 \%$ de los casos.

Menor frecuencia en variedades ricas en linfocitos y depleción linfocitaria.

Se dividen en:

Nodular predominante linfocitico.

Clásico.

Esclerosis nodular.

Rico en linfocitos.

Celularidad mixta.

Diseminación contigua entre las regiones linfáticas involucrando con menor frecuencia estructuras extraganglionares presentándose en un $80 \%$ de forma localizada.

Importantes factores pronósticos identi cados son: subtipo histológico, edad, valor de la velocidad de sedimentación globular, enfermedad avanzada (estadios III-IV), enfermedad voluminosa y la presencia de síntomas B).

Ganglios linfáticos grandes.
LNH

Sexto cáncer común con incidencia del 14 por 100,000 .

Mortalidad en EUA 2007 de 18,660 de 61,190 casos registrados.

Incremento exponencial de incidencia con la edad después de 20 años.

Se presenta con más frecuencia en raza blanca donde el riesgo para desarrollarse se calcula en 1:46 en varones y 1:56 en mujeres.

Se originan de las células $B$ representando el $85 \%$ de los casos y el $15 \%$ restante corresponde a neoplasias que se originan de células T y natural killer (NK).

Se dividen en agresivos e indolentes.

Agresivos: más comúnmente el linfoma difuso de células grandes tipo B EN UN 50\% y una tasa de sobrevida de $50 \%$.

Indolentes: linfoma folicular (pueden sufrir cambios hacia tipos más agresivos).

Diseminación hematógena y afecta regiones linfáticas discontinuas y sitios extraganglionares con más frecuencia.

Utilización del IPI( índice pronostico internacional) para estimar el pronóstico de los pacientes, tomando en cuenta la edad, valores séricos de la deshidrogenasa láctica (DHL),estado funcional (ECOG-KARNOFSKY), estadio de la enfermedad y presencia de enfermedad extraganglionar.

Ganglios linfáticos más grandes en comparación con el linfoma hodgkin.

*Descripción de Thomas Hodgkin ${ }^{15-17}$ en los primeros casos de linfoma (1832). 
Tabla 2. CLASIFICACIÓN DE LNH ( IWF)

\begin{tabular}{|c|c|c|}
\hline GRADO ALTO & GRADO INTERMEDIO & GRADO BAJO \\
\hline $\begin{array}{l}\text { - Células grandes inmuno- } \\
\text { blásticas } \\
\text { - Linfoma linfoblástico } \\
\text { - Célula pequeña no dividida } \\
\text { de Burkitt o no Burkittianas }\end{array}$ & $\begin{array}{l}\text { - Célula grande difusa } \\
\text { - Célula grande folicular } \\
\text { - Célula pequeña difusa divi - } \\
\text { dida } \\
\text { - Célula mixta grande y pe- } \\
\text { queña difusa }\end{array}$ & $\begin{array}{l}\text { - Leucemia linfocítica peque - } \\
\text { ña/ linfocítica crónica } \\
\text { - Célula folicular pequeña di - } \\
\text { vidida } \\
\text { - Célula folicular mixta gran - } \\
\text { de y pequeña. }\end{array}$ \\
\hline
\end{tabular}

*Clasi cación de LNH del sistema internacional de formulación de traba o (International Working ormulación IW ) con base en la apariencia. ${ }^{18}$

\section{CASO CLÍNICO}

Descripción del caso: Paciente varón de 84 años de edad, acudió al departamento de medicina familiar del Instituto de Seguridad y Servicios Sociales de los Trabajadores del Estado (ISSSTE) donde es referido al departamento de Cirugía Oral y Maxilofacial, donde se encontraron datos de hipertensión arterial sistémica, bajo tratamiento médico, sin datos de alergias con una historia de fiebre, pérdida de peso, astenia, cefalea, y aumento progresivo de volumen de aproximadamente 6 cm de diámetro a nivel de la región geniana del lado izquierdo, que tuvo un tiempo de evolución de dos meses. Al examen intraoral el paciente se encontró edentulo, con mucosa a nivel de la región yugal, con datos de pigmentación violácea y sin salida de material alguno. Al examen extraoral se observo marcada asimetría facial, perdida de la línea naso labial y evidente aumento de volumen e inmovilidad de la región afectada, acompañado de aumento de temperatura moderado a la palpación. Se determinó como una lesión solida no desplazable. Fig. 1,2

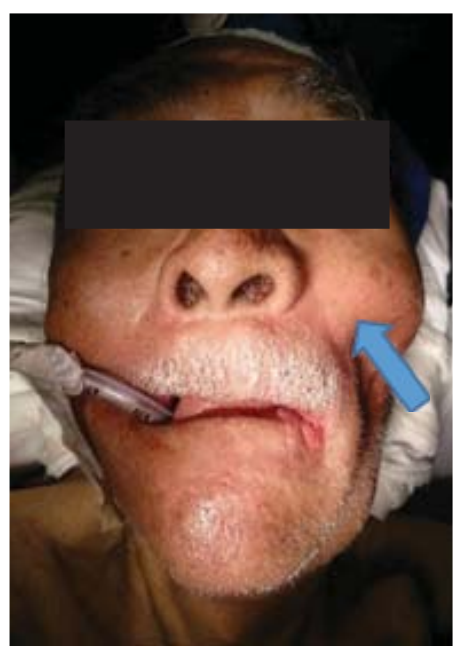

Figura 1. Paciente varón de 84 años con aumento de volumen a nivel de la región geniana. Flecha celeste.

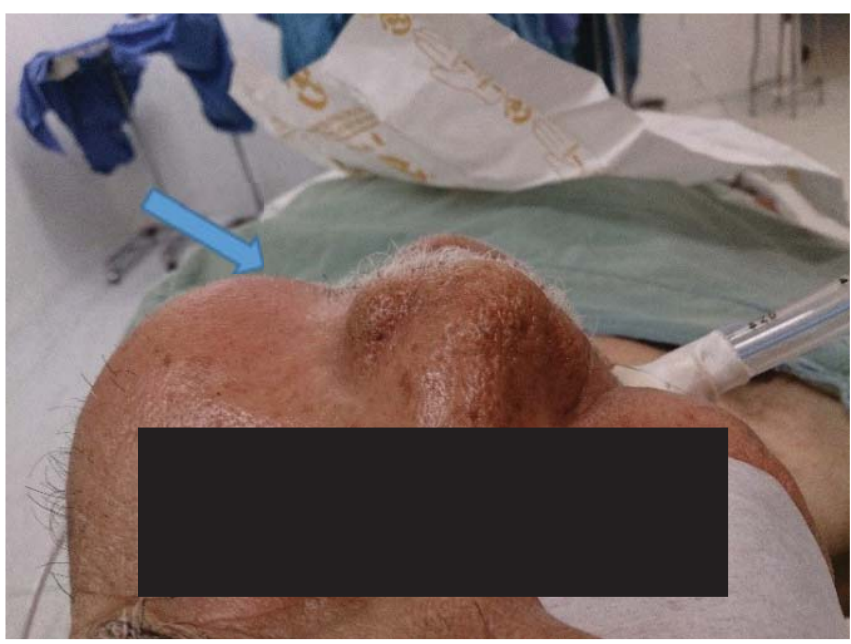

Figura 2. Examen extraoral: paciente con asimetría facial y borramiento de la línea naso labial. Flecha celeste. 
En el estudio de TAC simple y contraste se observó una zona isodensa a nivel de región geniana dependiente de estructura ósea, al contraste se apreció encapsulado, no infiltrativo en zona de músculos de la expresión facial, este estudio permitió realizar una adecuada evaluación de las características de la lesión donde se llevó acabo la medición de la lesión, la cual tenía dimensiones de $6 \times 5.5 \mathrm{~cm}$. La evaluación mediante reconstrucciones $3 \mathrm{D}$ de tejidos blandos y volumen óseo, permitió analizar de forma gráfica la presentación de la lesión y la relación con las estructuras adyacentes, donde permitió un adecuado análisis para un exitoso planeamiento quirúrgico. (Fig. 3) Fueron realizados cortes axiales y coronales (Fig. 4) para evidenciar el compromiso de las estructuras óseas permitieron apreciar la extensión de la lesión así como la dimensión de esta misma teniendo como resultado una lesión multilocular.
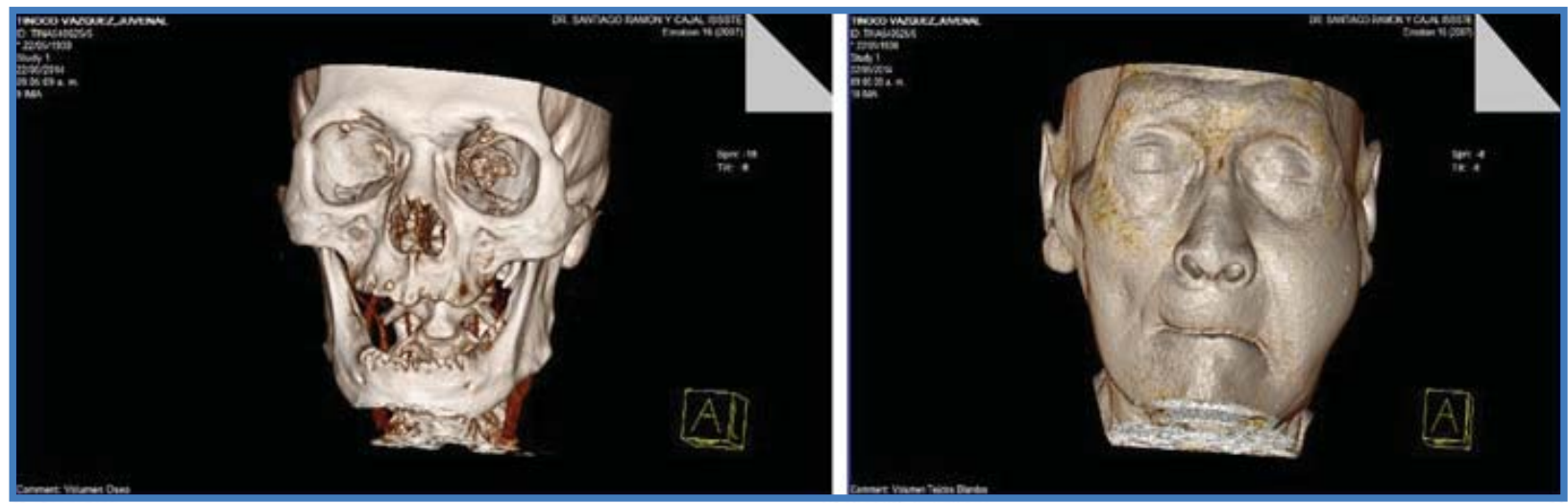

Figura 3.Reconstrucción volumétrica de tejidos blandos y volumen óseo, donde se observa aumento de volumen a nivel de la región geniana sin cambios osteolíticos erosivos evidentes.

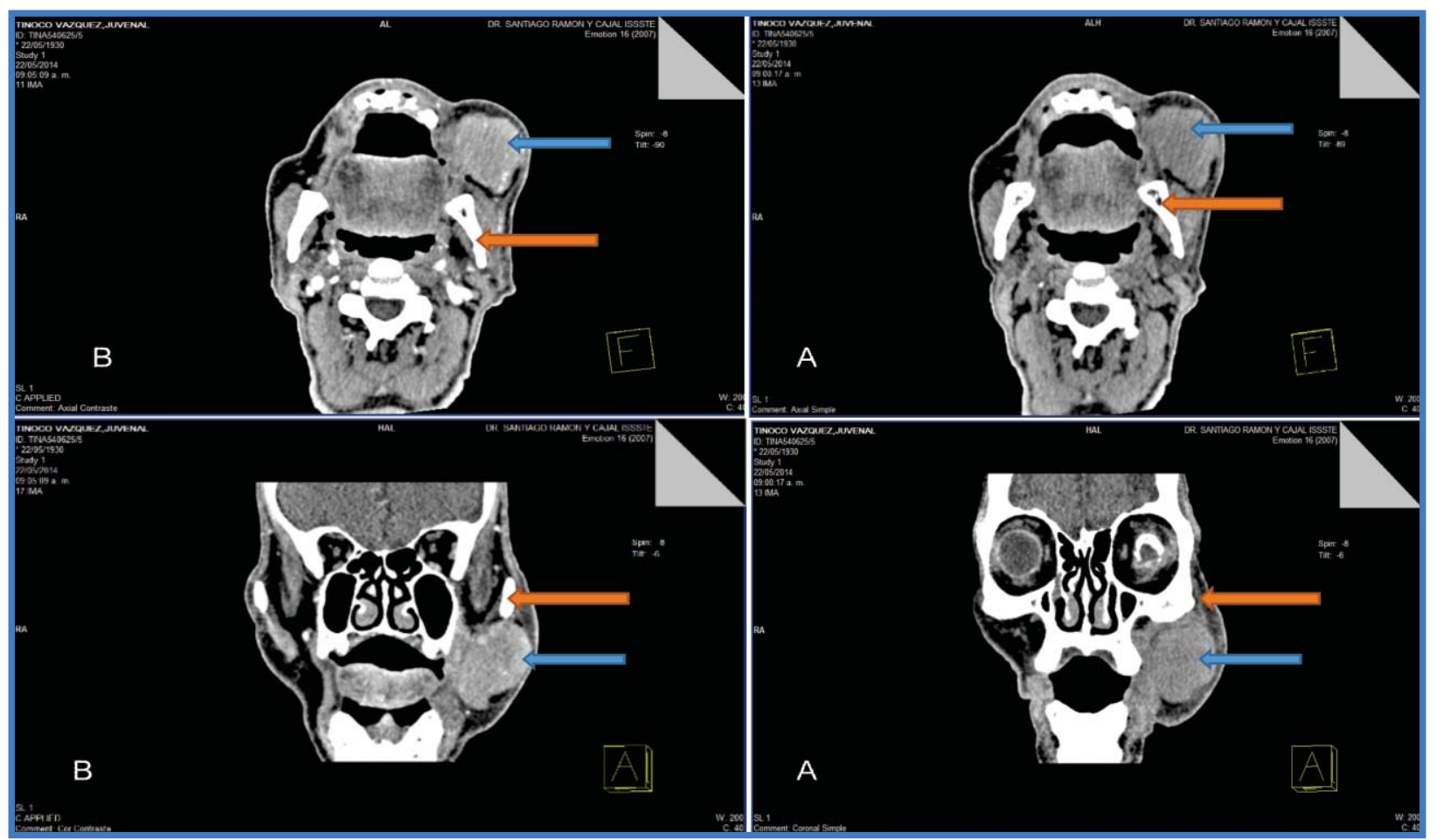

Figura 4. Corte Axial y Coronal Simple(A) y de Contraste (B) donde se observa una zona isodensa a nivel de re gión geniana indicada con flecha celeste dependiente de estructura ósea, indicada con flecha naranja, al contraste se aprecia encapsulada, no infiltrativa en zona de músculos de la expresión facial. 


\section{INTERVENCIÓN QUIRÚRGI- CA \\ DIAGNÓSTICO HISTOPATO- LÓGICO}

El cirujano oral maxilofacial decidió realizar una biopsia incisional de lesión, donde la zona de tumoración fue de $2 \mathrm{~cm}$ de diámetro, apreciando hueso maxilar de coloración semejante a zonas adyacentes, tejido granulomatoso no sangrante, así con tumoración de coloración cereza, se procedió a realizar una incisión sobre la misma sin presencia de sangrado profuso, donde fue retirado un segmento de $1 \times 1 \mathrm{~cm}$, el cual fue enviado para su estudio anatomopatológico con resultado de tejido inflamatorio crónico, sin evidencia de células malignas. Debido a las características que presentaba dicha lesión se consideró como un resultado poco confiable, por lo cual se tomó la decisión de programar una nueva intervención en donde se llevó acabo el tratamiento quirúrgico de biopsia exicional enviando dicha muestra a estudio anatomopatológico e inmunohistoquímica (Figura 5) donde obtuvimos como resultado; LINFOMA DIFUSO DE CÉLULAS GRANDES INMUNOFENOTIPO “B”. Se realizó la valoración posquirúrgica del paciente a $\operatorname{los} 8,10$ y 15 días mostrando una evolución favorable sin datos de dehiscencia de herida quirúrgica ,el paciente fue referido a servicio de Oncología.

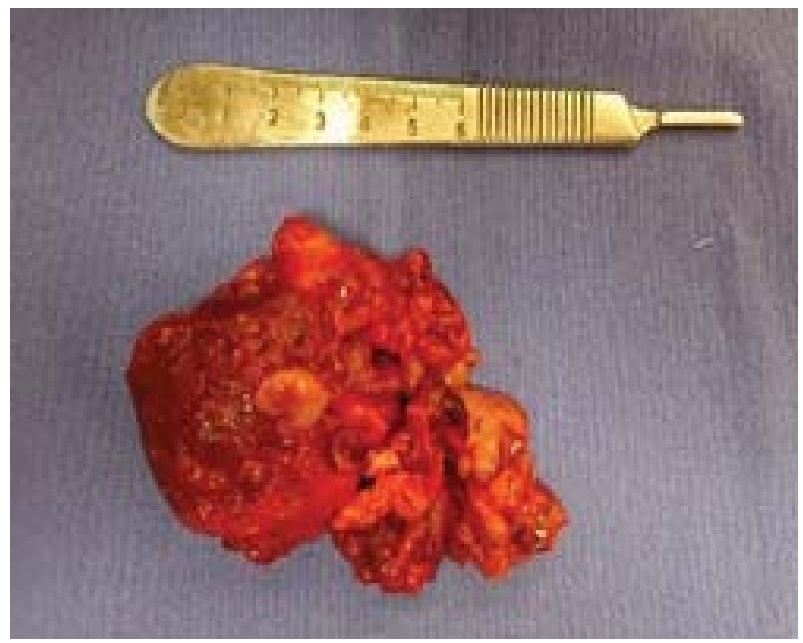

Figura 5. Lesión tumoral de dos meses de evolu ción de $6.5 \times 5.5 \mathrm{~cm}$, multilobulado, aspecto granulomatoso no sangrante adherido a tejido muscular. Muestra para estudio anatomopatológico.

El diagnóstico se confirmó mediante estudio histopatológico donde se observó una neoplasia maligna de estirpe linfoide caracterizada por una proliferación difusa de células grandes (Figura 7) donde se evidenció invasión a musculo estriado esquelético, dichas células presentaron núcleo prominente en las cuales se observo nucléolo prominente dispuesto de manera central (inmunoblastos) y en algunas de ellas múltiples nucléolos dispuestos a la periferia (centroblastos) (Figura 8). Mediante inmunohistoquímica fue, $\mathrm{BCL}-2^{\prime}+$, DC20+, KI-67 80\%+, MUM-1+, (Figuras 9-12), se confirmo el diagnóstico de linfoma difuso de células grandes inmunofenotipo B de tipo no centro germinal.

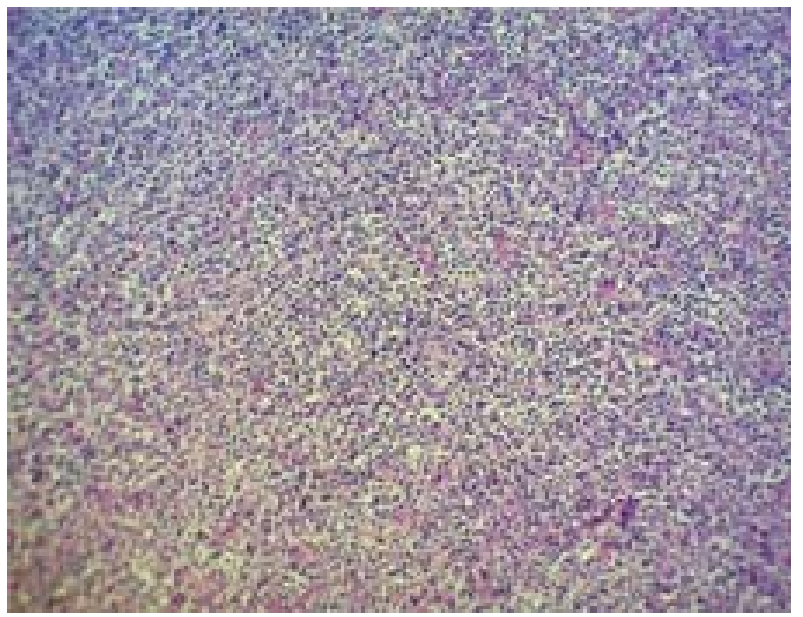

Figura 6. Proliferación difusa de células grandes

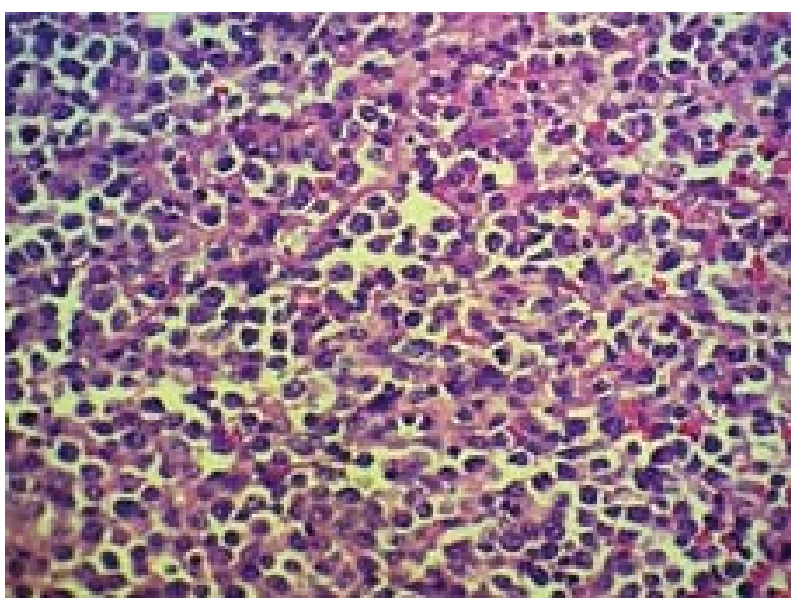

Figura 7. Invasión a músculo estriado esquelético 


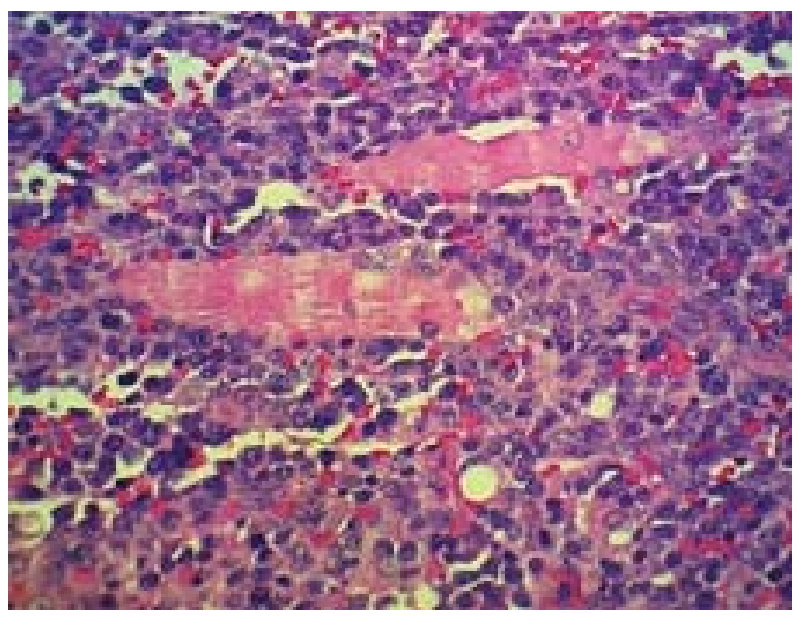

Figura 8. Células con núcleo prominente y nucléolo prominente dispuesto de manera central (inmunoblastos) y en algunas de ellas múltiples nucléolos dispuestos a la periferia (centroblastos).

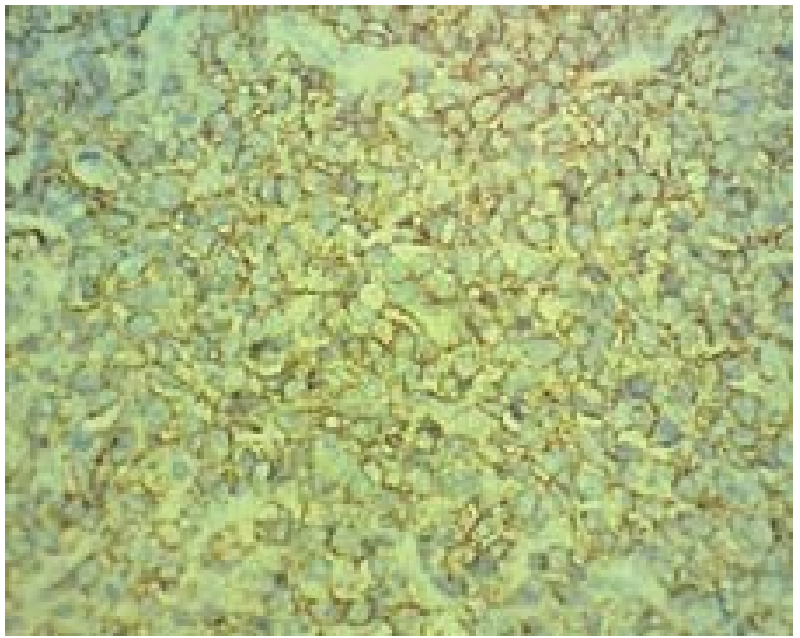

Figura 10. Reacción Inmunohistoquímica positiva para el marcador, DC20+.

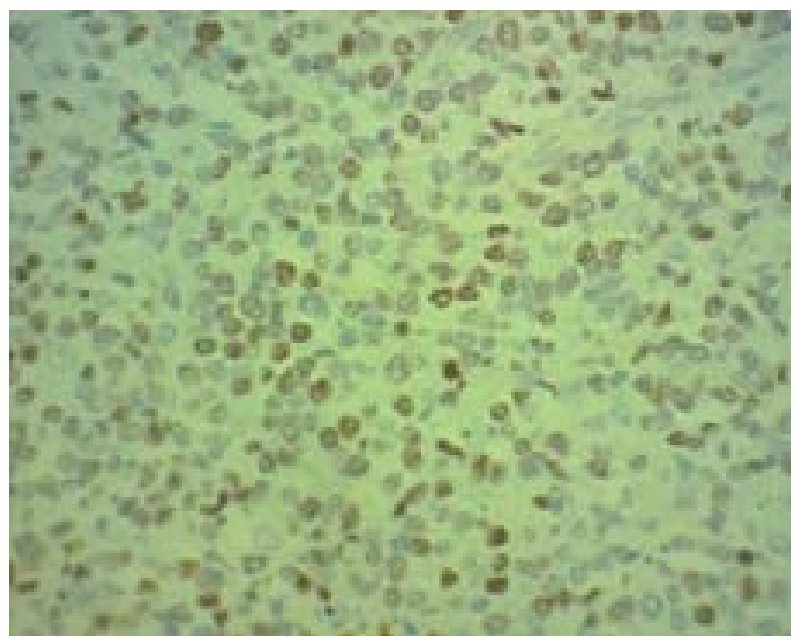

Figura 12. Reacción Inmunohistoquímica positiva para el marcador, MUM-1+.

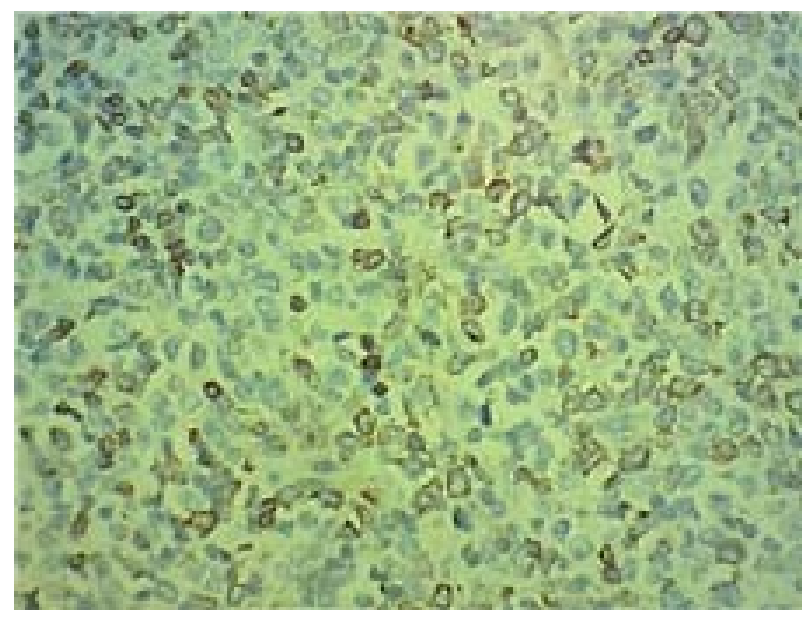

Figura 9. Reacción Inmunohistoquímica positiva para el marcador, BCL-2'+.

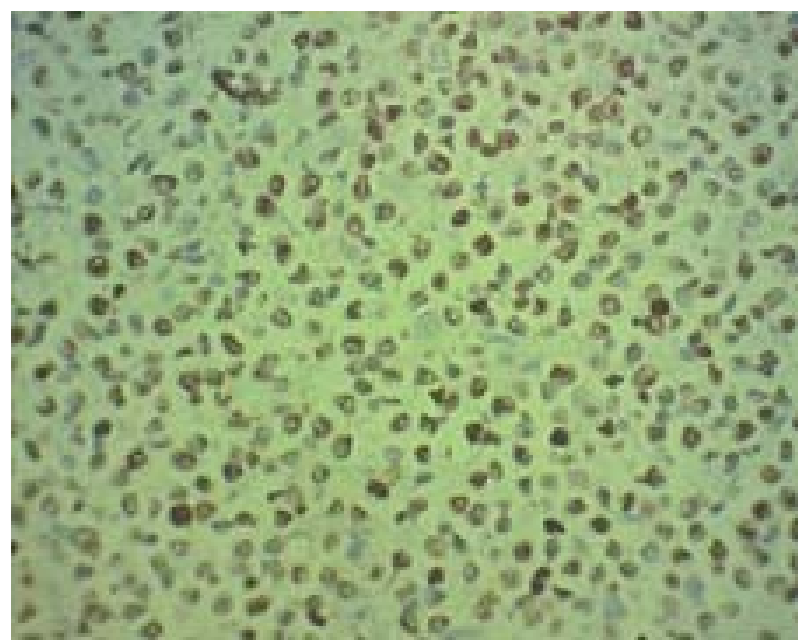

Figura 11. Reacción Inmunohistoquímica positiva para el marcador, KI-67 80\%+.

\section{DISCUSIÓN}

El caso clínico presentado es de gran interés por el lugar de proliferación del LDCGB ya que no es frecuente encontrarlo en región geniana. Es una neoplasia de células B del tamaño de un histiocito o de más de dos veces el de un linfocito, estos se subdividen en variantes morfológicas, subgrupos inmunofenotípicos, moleculares y entidades distintivas, quedando un grupo sin características propias llamado: NOS (not otherwise specified). Es importante conocer el tipo, ya que de ello depende cómo se trata el cáncer. Puede presentarse de novo como fue en este caso o por 
transformación de un linfoma no Hodgkin de células pequeñas. Dicha tumoración descansaba sobre hueso maxilar y hueso cigomático reposando en la inserción del periostio, esto sin presentar cambios osteolíticos erosivos en comparación de los LNH con compromiso óseo, donde alrededor del $80 \%$ presentan cambios osteolíticos erosivos en las radiografías, otros tienen una apariencia radiográfica esclerótica o mixta. ${ }^{9}$ Los subgrupos de linfomas B pueden distinguirse utilizando marcadores de inmunohistoquímica que junto con la evaluación del estadio clínico y del Índice Pronóstico Internacional (IPI), pueden determinar el pronóstico según lo indican varios estudios. ${ }^{14}$

Generalmente este grupo de Linfomas tiene un tratamiento quimioterapéutico, sin embargo, los resultados de los pacientes afectados por este linfoma son muy variados, el tratamiento convencional con esquemas de quimioterapia pueden curar a muchos pacientes. Los avances en el tratamiento del LDCGB en los últimos años, en especial la asociación de anticuerpos monoclonales, han conseguido mejorar los resultados en muchos enfermos. Las guías terapéuticas para el LDCGB ofrecen diferentes estrategias para pacientes con estadios localizados y para estadios avanzados. ${ }^{19}$ Una de las estrategias para mejorar los resultados en pacientes de mayor riesgo es intensificar la dosis de quimioterapia inicial. Varios estudios han abordado esta cuestión. El grupo alemán GLSG (German Lymphoma Study Group) demostró el beneficio que tiene la administración de quimioterapia en dosis densas y su eficacia en los pacientes mayores con LDCGB. ${ }^{20}$ El conocimiento de la biología de las resistencias y de la actividad de estos nuevos fármacos en los diferentes subtipos de LDCGB resultará de especial trascendencia para seleccionar las nuevas combinaciones de tratamiento en el futuro. ${ }^{19}$

\section{CONCLUSIONES}

Es necesario que los odontólogos conozcan la importancia del diagnóstico en este tipo de lesión, la cual tiene una presentación clínica más agresiva al momento del diagnóstico. Su locali- zación en la región geniana no es frecuente por lo tanto es indispensable el uso de marcadores para inmunohistoquímica que en conjunto con la evaluación del estadio clínico y el índice pronóstico internacional (IPI), pueden determinar el tipo de lesión, siendo imprescindible diferenciar un LDCGB en centroblástico o inmunoblástico. Debido a que constituye un factor de riesgo significativo es importante conocer las variantes morfológicas y de localización de los LDCGB, que permitirán realizar un diagnóstico positivo de la neoplasia y ampliar la lista del diagnóstico diferencial, llevando acabo el tratamiento y seguimiento apropiado.

\section{REFERENCIAS BIBLIOGRÁFICAS}

1. Frenk-Mora J, Ruelas-Barajas E, Tapia-Conyer R, Castañón- Romo R et al. Compendio de Cáncer 2000/ Mortalidad/ Morbilidad. Registro Histopatológico de Neoplasias Malignas. Dirección General de Epidemiología. www.epi.org.mx

2. National Cancer Institute. Summary and description of a working formulation for clinical usage. The non-Hodgkin's Lymphoma Pathologic Classification Project. Cancer 1982; 49: 2112-2135.

3. Hervás-Ontiveros A, España-Gregori E, Hernández-Martínez P, J. Vera-Sempere F, Díaz-Llopis M. Afectación orbitaria por linfoma no Hodgkin de células T NK. Archivos de la sociedad española de oftalmología. 2014; 89(11): 450-453.

4. Loachim HL, Dorsett B, Cronin W et al. Acquired immunodeficiency syndrome-associated lymphomas: Clinical, pathologic, immunologic, and viral characteristics of 111 cases. Human Pathol 1991; 22: 659673.

5. Romero GM, Hernández GM, Durán PM, Mandujando AG, Alcántara VA. Linfoma B difuso de células grandes. Características patológicas y de inmunofenotipo en 148 pacientes estudiados en el Hospital General de México. Revista Médica del Hospital General de México S.S. 2006;69(4):192-96.

6. Murrieta H, Villalobos A, García S. Linfoma: Aspectos clínicos y de imagen. Anales de Radiología México. 2009; 1: 81-97.

7. Jaffe ES, Harris LN, Stein H, Vardiman WJ et al. Tumours of haematopoietic and lymphoid tissues. Pathology and genetics. Lyon: IARC Press, 2001; 171187.

8. SEOM [sede Web]. Madrid: Sociedad Española de Oncología Médica. [actualización: 11 Marzo 2015 13:02, / revisión: 01 Marzo 2016 12:24; acceso: 10 
Marzo 2016 19:02]. Linfomas No Hodgkin [aproximadamente 3 pantallas]

9. Edeiken-Monroe B, Edeiken J, Kim EE. Radiologic concepts of lymphoma of bone. Radiol Clin North Am. 1990; 28: 841.

10. Harris NL, Jaffe ES, Stein H, Banks PM, Chan JK, Cleary ML et al. A Revised European- American Classification of Lymphoid Neoplasms: A proposal from the international lymphoma study group. Blood. 1994;84(5): 1361-92.

11. Engert A, Eichenauer DA, Dreyling M, On behalf of the ESMO Guidelines Working Group. Hodgkin's lynphoma: ESMO clinical recommendations for diagnosis, treatment and follow-up. Annals of Oncology. 2009; 20(4): iv 108-iv 109.

12. Tilly H, Vitolo U, Wallewsky J, Gomes da Silvia M, Shpilberg O, André M, et al. Diffuse large B-cell lymphoma (DLBCL): ESMO clinical practice guidelines for diagnosis, treatment and follow-uo. 2009; 23(7): vii $78-$ vii82.

13. Pappa VI, Hussain HK, Reznek RH, Whelan j, Norton AJ, Wilson AM, et al. Role of image-guided core-needle biopsy in the management of patients with lymphoma. J Clin Oncol. 1996;14(9):2427-30.

14. Campo E, Swerdlow SH, Harris NL, Pileri S, Stein H, Jaffe ES. The 2008 WHO classification of lymphoid neoplasms and beyond: evolving concepts and practical applications. Blood. 2011;117(19):5019-5032.

15. Hellman S. A brief consideration of Thomas Hodgkin and his times. In: Mauch PM, Armitage JO, Diehl V, Hoppe RT, Weiss LM, editors. Hodgkin's Disease. Philadelphia: Lippincott, Williams \& Wilkins; 1999. pp. 3-7.

16. Hodgkin. On some Morbid Appearances of the $\mathrm{Ab}$ sorbent Glands and Spleen.Medico-chirurgical transactions. 1832;17:68-114.

17. Murias A. Seguimiento a largo plazo de pacientes con linfoma no hodgkin tratados con ciclofosfamida, adriamicina, vincristina y prednisona (CHOP) (tesis doctoral). Las Palmas de Gran Canaria. Universidad de las Palmas de Gran Canaria. 2009.

18. Chan JK. The new World Health Organization classification of lymphomas: the past, the present and the future. Hematol Oncol. 2001;19:129-150.

19. Grande C.. Actualización del tratamiento del linfoma difuso de células grandes B. En: Dr. Adrián Alegre Amor, Servicio de Hematología, Hospital Universitario de la Princesa Madrid. Cuadernos de hematología. $1^{\text {a }}$ ed. Fundación Leucemia y Linfoma; 2011. pp.112.

20. Pfreundschuh M, Schubert J, Ziepert M et al. Six versus eight cycles of biweekly CHOP-14

with or without rituximab in elderly patients with aggressive $\mathrm{CD} 20+$ B-cell lymphomas: a randomized controlled trial (RICOVER-60). Lancet Oncol 2008;9:105-116. 